\title{
B.C.G. TUBERCULIN
}

\author{
BY \\ JOHN LORBER \\ From the Department of Child Health, the University of Sheffield
}

(RECEIVED FOR PUBLICATION APRIL 30, 1957)

It is well known that after Bacille Calmette-Guérin (B.C.G.) vaccination the degree of allergy as shown by the tuberculin test is of a lesser order than that after infection with virulent tubercle bacilli. For this reason it may be necessary to perform several successively stronger tuberculin tests up to 100 units of old tuberculin (Mantoux 1/100) before a positive post-vaccination test is obtained. Several tests, however, are inconvenient to patients and physicians alike. In addition, a test with 100 tuberculin units may well give rise to non-specific false positive reactions.

Several investigators abroad have reported that a tuberculin prepared from the B.C.G. substrain of tubercle bacilli is a more sensitive indicator of tuberculin allergy in vaccinated persons (Bluhm, 1949; Hagberg, 1950; Lind and Holm, 1943; Magnusson, Lithander and Hagberg, 1949; Ruziczka, 1952a and b; Quaiser, 1954). As we required a sensitive quantitative test to evaluate the antigenic properties of several batches of newly introduced freeze-dried B.C.G. vaccines of British manufacture (Lorber, Hart, Farmer and Muggleton, 1956; Lorber, Farmer and Muggleton, 1957), we decided to conduct a controlled trial of B.C.G. tuberculin as one of the post-vaccination tests.

\section{Preparation of B.C.G. Tuberculin}

The B.C.G. (Copenhagen strain) tuberculin was grown at $37^{\circ} \mathrm{C}$. for eight weeks on Sauton's medium containing $4 \%$ glycerol. The cultures were heated for three hours at $100^{\circ} \mathrm{C}$. after which the growth was collected by filtration and discarded. The clear filtrate was reduced to $10 \%$ of its original volume by low pressure distillation. An equal volume of $20 \%$ aqueous trichloracetic acid solution was then added slowly with continuous stirring and the solution kept at $4^{\circ} \mathrm{C}$. overnight. The precipitate which had formed was collected by centrifuging and washed three times with distilled water. The precipitate, suspended in distilled water, was then dialyzed against running tap water for six hours and then against frequent changes of distilled water for one week at $4^{\circ} \mathrm{C}$. The suspension was then redissolved by the addition of the minimum necessary quantity of sodium hydroxide in solution and the $p \mathrm{H}$ then readjusted to $7 \cdot 0$ with hydrochloric acid. After sterilization by filtration through a Seitz filter, $0.5 \%$ phenol was added.

The concentrated tuberculin solution was then standardized against international standard purified protein derivative (P.P.D.) tuberculin by the method of Long, Miles and Perry (1954). For use, the concentrated stock solution was diluted in $10 \%$ glycerol, $0.5 \%$ phenol solution to contain 10 units in $0.1 \mathrm{ml}$. The solution was filled into $2.0 \mathrm{ml}$. glass ampoules.

The B.C.G. tuberculin was used in the following forms:

(1) A solution of $1 / 1000$ for intradermal use by the Mantoux technique, containing 10 T.U. per $0 \cdot 1 \mathrm{ml}$. dose.

(2) A solution containing 10,000 T.U./ml. for percutaneous use with the multiple puncture (Heaf, 1951) technique; and

(3) A tuberculin jelly for percutaneous use containing 60,000 units of B.C.G. tuberculin. (This is the same concentration of tuberculin as is used in the standard old tuberculin jelly, 'tradermin ', of Allen and Hanbury.)

\section{Present Investigation}

(a) Type of Subjects. In order to assess the value of B.C.G. tuberculin in vaccinated subjects it was also necessary to ascertain that it does not give false positive reactions in non-tuberculous and in unvaccinated persons and that it gives reliable positive reactions in persons with active or inactive tuberculosis. For this reason controlled clinical trials were carried out on the following groups of subjects, numbering 987 in all.

(1) Uninfected and unvaccinated children and young adults (191 subjects).

(2) Children with active tuberculous infections (80 subjects).

(3) Young adults (students and nurses) with inactive or latent tuberculous infections (74 subjects).

(4) Infants, children and young adults (642 subjects) who had been vaccinated with either the liquid Danish B.C.G. vaccine or with one of five freeze-dried vaccines of different viable cell counts. These had been vaccinated a few weeks to several years before they were tested with B.C.G. tuberculin.

(b) Methods of Testing. By far the largest number were tested by the intradermal (Mantoux) route. Concurrent tests were performed in 987 subjects as follows:

(1) Five hundred and seventy-six subjects received by 
Mantoux technique 10 T.U. of B.C.G. tuberculin compared with 10 T.U. of old tuberculin.

(2) One hundred and fifty-one subjects received by Mantoux technique 10 T.U. of B.C.G. tuberculin compared with 100 T.U. of old tuberculin.

(3) One hundred and seven subjects received 10 T.U. of B.C.G. tuberculin intradermally compared with P.P.D. tuberculin $(100,000$ T.U. per ml.) by multiple puncture test (Heaf, 1951).

(4) Seventy-six subjects received B.C.G. tuberculin $(10,000$ T.U.) compared with P.P.D. tuberculin $(100,000$ T.U.) by multiple puncture test.

(5) Seventy-seven subjects received B.C.G. tuberculin jelly $(60,000$ T.U. per g.) compared with O.T. tuberculin jelly $(60,000$ T.U. per g.) percutaneously without the use of flour paper.

An induration of $6 \mathrm{~mm}$. or more was taken as positive in the case of the Mantoux tests, and four papules or more in the case of the jelly tests. The criteria of Heaf were used for the assessment of the multiple puncture tests. Dr. P. W. Gifford performed all the tests on adults.

\section{Results}

(1) Tuberculin-negative Children. There were 191 subjects who were considered to be tuberculin negative as a result of the tests. In 187 of these $(98 \%)$ no reaction whatever followed either test. The details of the tests are set out in Table 1. The

TABLE 1

TUBERCULIN TESTS IN TUBERCULIN NEGATIVE SUBJECTS

\begin{tabular}{|c|c|c|}
\hline Test 1 & Test 2 & Number Tested \\
\hline $\begin{array}{l}\text { B.C.G. (T) } 10 \text { T.U. } \\
\text { B.C.G. (T) } 10 \text { T.U. } \\
\text { B.C.G. (T) (Heaf) } \\
\text { B.C.G. (T) jelly }\end{array}$ & $\begin{array}{l}\text { O.T. } 10 \text { T.U. } \\
\text { P.P.D. (Heaf) } \\
\text {.P.P.D. (Heaf) } \\
\text { O.T. jelly }\end{array}$ & $\begin{array}{l}93 \\
53 \\
22 \\
23\end{array}$ \\
\hline Total & & 191 \\
\hline
\end{tabular}

remaining four gave some reaction but below the minimal criteria of a positive test. One, a child of 13 , had a discoloration of $17 \mathrm{~mm}$. in diameter but no induration at the site of the B.C.G. tuberculin injection (10 T.U.) while there was no reaction at all to 10 units of old tuberculin. When retested, there was no reaction to either antigen and after B.C.G. vaccination there was no untoward or accelerated development at the vaccination site. Two other children, aged 3 and 10, gave similar results. The fourth case was an adult who was tested with 10 units of B.C.G. tuberculin intradermally and who showed an induration of $3 \mathrm{~mm}$. in diameter 72 hours later. A concurrent multiple puncture test with P.P.D. tuberculin produced papules which were just palpable. The test was repeated and the same result was obtained.

There were 104 other subjects who gave no reaction to 10 units of B.C.G. tuberculin but had no concurrent tests with old tuberculin.

It can be concluded, therefore, that B.C.G. tuberculin in the three forms used did not give false positive reactions when compared with established methods of tuberculin testing with O.T. or P.P.D.

TABLE 2

TUBERCULIN TESTS IN TUBERCULOUS SUBJECTS

\begin{tabular}{|c|c|c|c|}
\hline Test & $\begin{array}{l}\text { Number } \\
\text { Tested }\end{array}$ & $\begin{array}{l}\text { Number } \\
\text { Positive }\end{array}$ & $\begin{array}{c}\text { Average } \\
\text { Induration } \\
\text { (mm.) }\end{array}$ \\
\hline 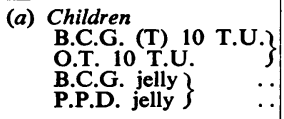 & $\begin{array}{l}54 \\
54 \\
26 \\
26\end{array}$ & $\begin{array}{l}54 \\
52 \\
26 \\
24\end{array}$ & $\begin{array}{l}22 \\
16 \\
-\end{array}$ \\
\hline $\left.\begin{array}{l}\text { (b) Adults (inactive cases) } \\
\text { B.C.G. (T) } 10 \text { T.U.) } \\
\text { P.P.D. (Heaf) } \\
\text { B.C.G. (T) (Heaf) } \\
\text { P.P.D. (Heaf) }\end{array}\right\}$ & $\begin{array}{l}53 \\
53 \\
21 \\
21\end{array}$ & $\begin{array}{l}53 \\
52 \\
20 \\
21\end{array}$ & - \\
\hline
\end{tabular}

(2) Tuberculous Children. Concurrent tests with B.C.G. tuberculin and with O.T. were carried out on 80 children with known recent tuberculous infection. Most of them had uncomplicated primary tuberculosis but 12 cases of miliary tuberculosis or meningitis are included among them. In 54 intradermal tests (10 T.U.) and in 26 the jelly tests were used. A positive result was obtained with B.C.G. tuberculin in all cases. Four children tested with O.T. (two Mantoux tests and two jelly tests) gave a negative result. All four were bacteriologically proven cases of meningitis or miliary tuberculosis. For example, an infant of 4 months of age was tested soon after her admission with miliary tuberculosis and again three months later. The response of 10 units of B.C.G. tuberculin was an induration of 10 and $7 \mathrm{~mm}$. respectively, and to 10 units of O.T. a papule of $2 \mathrm{~mm}$. diameter on the first occasion and no reaction at all on the second occasion.

The average diameter of induration with intradermal B.C.G. tuberculin in 54 children was $22 \mathrm{~mm}$. (range 7-50 mm.) and with O.T. $16 \mathrm{~mm}$. (range 6-27 mm.). In four children the reaction to O.T. was larger, in four they were equal and in 46 the B.C.G. tuberculin gave the stronger reaction.

Of the 26 children tested with the jelly, the reaction produced by the B.C.G. tuberculin was generally more widespread and more definite.

It appears, therefore, that unit for unit the B.C.G. tuberculin gave stronger reactions in tuberculous 
children than O.T. and that some children with a low degree of allergy gave negative reactions of O.T. and positive ones to B.C.G. tuberculin.

(3) Adults with Latent or Quiescent Tuberculosis. Among 149 young adults (nurses and students) who underwent routine tuberculin testing 74 gave a positive result. There was no clinical or radiological evidence of active tuberculosis in any of these. Fifty-three had tests with 10 T.U. of B.C.G. tuberculin intradermally and concurrent multiple puncture tests with P.P.D. tuberculin. Unequivocally positive tests were obtained in 52. In the 53rd the B.C.G. tuberculin gave an induration of $15 \mathrm{~mm}$. but there were only just palpable papules with the multiple puncture P.P.D. test. The same result was obtained on repeating the tests.

Twenty-one subjects had concurrent multiple puncture B.C.G. tuberculin and P.P.D. tuberculin tests. The B.C.G. tuberculin contained 10 times fewer units per millilitre than the P.P.D. tuberculin. Twenty gave positive tests to both, but one was negative to B.C.G. and positive to the P.P.D. test. The P.P.D. test gave a stronger reaction in 10, an equal reaction was found in nine, and B.C.G. tuberculin gave a stronger reaction in one.

It is seen, therefore, that among these 74 subjects there was good agreement between B.C.G. tuberculin and P.P.D. tuberculin in 72. In the remaining two one or the other of the two tuberculins gave a negative reaction.

(4) Children and Adults after B.C.G. Vaccination. By far the largest group (642 subjects) were infants, children and young adults who were tested three weeks to several years after B.C.G. vaccination. Of these, 580 infants and children had intradermal tests with 10 units of B.C.G. tuberculin concurrently with either 10 units of O.T. (429 cases) or 100 units of O.T. (151 cases). In addition, 29 children had concurrent jelly tests and 33 young adults had concurrent multiple puncture tests with B.C.G. and P.P.D. tuberculins. All the 33 adults and 203 infants and children had been vaccinated with the Danish liquid B.C.G. vaccine and 406 children had been vaccinated with one of five different batches of freeze-dried B.C.G. vaccine.

The details of the vaccines, the subjects, the time which had elapsed after vaccination and the results of the intradermal tests are fully set out in Table 3 . A positive result was obtained with the B.C.G. tuberculin in $567(97.7 \%)$ infants and children. Eight of the 13 negative reactors had been vaccinated with two early batches of freeze-dried vaccine now

TABLE 3

COMPARISON OF RESULTS OBTAINED WITH INTRADERMAL B.C.G. TUBERCULIN AND INTRADERMAL OLD TUBERCULIN AT DIFFERENT STRENGTHS

\begin{tabular}{|c|c|c|c|c|c|c|c|c|c|c|c|c|}
\hline \multicolumn{2}{|c|}{ Vaccine } & \multirow[b]{3}{*}{ Subjects } & \multirow[b]{3}{*}{$\begin{array}{l}\text { Period after } \\
\text { Vaccination }\end{array}$} & \multicolumn{9}{|c|}{ Tuberculin Tests } \\
\hline \multirow[b]{2}{*}{ Type } & \multirow[b]{2}{*}{$\begin{array}{c}\text { Viability } \\
\text { Count per } \\
\text { Millilitre } \\
\text { (approximate) }\end{array}$} & & & \multicolumn{3}{|c|}{ B.C.G. Tuberculin ( 10 T.U.) } & \multicolumn{3}{|c|}{ O.T. (10 units) } & \multicolumn{3}{|c|}{ O.T. (100 units) } \\
\hline & & & & 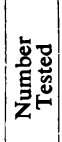 & 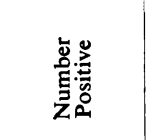 & 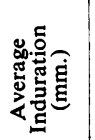 & 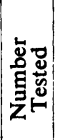 & 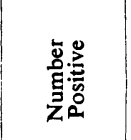 & 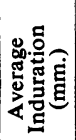 & 岁它 & 离: & 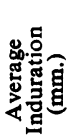 \\
\hline Danish & $13 \times 10^{\beta}$ & Infants 6-12 weeks & 6-12 weeks & 157 & $156(99 \cdot 9 \%)$ & $12 \cdot 1$ & 96 & $47(48 \cdot 9 \%)$ & $4 \cdot 9$ & 62 & $62(100 \%)$ & $12 \cdot 6$ \\
\hline Danish & $13 \times 10^{8}$ & Contact children & 1 yr. or more & 46 & $46(100 \%)$ & $18 \cdot 0$ & 46 & $34(73 \cdot 9 \%)$ & $9 \cdot 0$ & - & - & - \\
\hline $\begin{array}{l}\text { F.D. } \\
\text { Batch } 50\end{array}$ & $0 \cdot 1 \times 10^{3}$ & $\begin{array}{l}\text { 1-year-old children } \\
\text { vaccinated at birth }\end{array}$ & 1 year & 83 & $83(100 \%)$ & $17 \cdot 0$ & 80 & $54(67 \cdot 5 \%)$ & $7 \cdot 0$ & 3 & 3 & $19 \cdot 0$ \\
\hline $\begin{array}{l}\text { F.D. } \\
\text { Batch 93a }\end{array}$ & $11 \times 10^{\beta}$ & Infants $6-12$ weeks & 6-12 weeks & 141 & $139(98 \cdot 6 \%)$ & $11 \cdot 1$ & 73 & $32(43 \cdot 8 \%)$ & $4 \cdot 1$ & 67 & $67(100 \%)$ & $11 \cdot 1$ \\
\hline $\begin{array}{l}\text { F.D. } \\
\text { Batch 93a }\end{array}$ & $11 \times 10^{6}$ & $\begin{array}{l}\text { Children aged } \\
4 \text { months-14 years }\end{array}$ & 3 weeks & 13 & $13(100 \%)$ & $15 \cdot 0$ & 13 & $10(76 \cdot 9 \%)$ & $10 \cdot 0$ & - & - & - \\
\hline $\begin{array}{l}\text { F.D. } \\
\text { Batch } 77\end{array}$ & $23 \times 10^{6}$ & $\begin{array}{l}\text { 1-year-old children } \\
\text { vaccinated at birth }\end{array}$ & 1 year & 111 & $109(98 \cdot 2 \%)$ & $20 \cdot 0$ & 92 & $85(92.4 \%)$ & $11 \cdot 0$ & 19 & $19(100 \%)$ & $23 \cdot 0$ \\
\hline \multirow{2}{*}{$\begin{array}{l}\text { F.D. } \\
\text { Batches } \\
42 \text { and } 48\end{array}$} & Variable & 2-year-old children & 2 years & 29 & $21(72 \cdot 4 \%)$ & $10 \cdot 0$ & 29 & $15(51 \cdot 7 \%)$ & $6 \cdot 0$ & - & 一 & - \\
\hline & & & & 580 & $567(97 \cdot 7 \%)$ & & 429 & $277 \cdot(645 \%)$ & & 151 & $151(100 \%)$ & \\
\hline
\end{tabular}


not in use. Of the 429 children tested with 10 T.U. of O.T., only $277(64.6 \%)$ gave a positive result, and of the 151 tested with 100 T.U. of O.T., all gave a positive result. None of the last group had been vaccinated with the early batches of B.C.G. tuberculin.

The average diameter of induration produced by the tests varied according to the type of vaccine used and the interval following vaccination. The lowest average diameter with B.C.G. tuberculin was $10.0 \mathrm{~mm}$. in a small group vaccinated with a weak vaccine and the highest was 20.0 in a group vaccinated with the vaccine of the highest viable count $\left(23 \times 10^{6} / \mathrm{ml}\right.$.). The average induration was consistently much lower in each group tested with 10 T.U. of O.T. $(4 \cdot 1-10 \cdot 0 \mathrm{~mm}$.) and a little higher in those tested with 100 T.U. of O.T. $(11 \cdot 1-23.0 \mathrm{~mm}$.) as compared with the induration produced by 10 T.U. of B.C.G. tuberculin.

Of the 29 children who were tested with the two types of tuberculin jelly, all gave a positive reaction to the B.C.G. tuberculin jelly and only 22 were positive to the O.T. jelly. Of the positive reactors 19 gave strongly positive tests to B.C.G. tuberculin as compared with only two to old tuberculin.

Of 33 adults tested with the multiple puncture technique, all gave positive results to both tests. The B.C.G. tuberculin, whose tuberculin content was one-tenth that of the P.P.D. tuberculin, gave nevertheless stronger reactions in three. In the others the reactions were of equal grade.

\section{Discussion}

This investigation shows that B.C.G. tuberculin may be satisfactorily used as a standard tuberculin test to detect tuberculous allergy in infected persons and to exclude tuberculous infection in non-infected persons. In this respect it seems to be as effective as old tuberculin. In fact, in the tuberculous children 10 units of B.C.G. tuberculin intradermally or the B.C.G. tuberculin jelly gave consistently more positive reactions than the corresponding preparation of old tuberculin. This is particularly valuable in cases of miliary or meningeal tuberculosis, because of the well known anergy in these conditions. Nevertheless, the most important role of B.C.G. tuberculin is the detection of tuberculous allergy in B.C.G. vaccinated children. As has been shown, 10 units of B.C.G. tuberculin by the Mantoux test detected tuberculin allergy in $97.7 \%$ of vaccinated children, whereas 10 units of old tuberculin used in the same way and at the same time in the same children only produced a positive reaction $64.5 \%$. Ten units of B.C.G. tuberculin were virtually as effective in showing tuberculin conversion as
100 units of old tuberculin, without the same risk of giving false positive results. Further, a single test with 10 units was sufficient to detect tuberculin allergy in virtually all vaccinated and tuberculous subjects without having recourse to two or more consecutive tests.

Unfortunately relatively little B.C.G. tuberculin was available for the preparation of a tuberculin jelly, which is extravagant in tuberculin content. Nevertheless the findings in 77 children who had concurrent tests with B.C.G. and old tuberculin jelly of identical tuberculin content confirm the results obtained in the much larger series of subjects who were tested with the Mantoux technique. It will be of great interest to investigate a B.C.G. tuberculin jelly on a larger scale once supplies become more plentiful. Now that the quantitative aspects of testing with B.C.G. tuberculin have been established by controlled trials with Mantoux tests, the potential advantages of a tuberculin test which is reliable under all conditions and which does not require any form of injection (or abrasion) are obvious and require further study.

In the 76 adult subjects in whom B.C.G. tuberculin was used by the multiple puncture test, the results were again similar to those obtained by the intradermal or the jelly tests. The P.P.D. tuberculin used in these tests was 10 times more concentrated, yet in half the cases of natural infection the intensity of the reaction following the two tests was equal. In the other half the P.P.D. tuberculin gave the stronger reaction. In the vaccinated subjects there was no appreciable difference in the intensity of the reaction in spite of the difference in the strength of the two tuberculins.

It would be interesting to know whether it is possible to distinguish between naturally or artificially induced tuberculin sensitivity with the help of B.C.G. tuberculin. Although this aspect has not been the primary object of this investigation, it does not appear that this is any more possible with B.C.G. tuberculin than with old tuberculin. Although the average diameter of induration of the Mantoux lesion following the injection of 10 units of B.C.G. tuberculin was larger $(22 \mathrm{~mm}$.) in tuberculous than in vaccinated children $(10.0 \mathrm{~mm} .-20.0 \mathrm{~mm}$. according to type of B.C.G. used and the time which elapsed since vaccination), there was such a large area of overlap that an attempt at differential diagnosis on this ground would be unjustified.

In conclusion, in B.C.G. tuberculin we have an effective and reliable agent for the detection of tuberculin sensitivity. It is particularly useful for tests after B.C.G. vaccination, as it appears to be much more potent than old tuberculin when used 
in weaker dilutions, thus eliminating the possibility of false positive reactions and the need for several tests. These results fully confirm the findings of those workers abroad whose work has been cited in the introduction. Of course, in these cases B.C.G. tuberculin may measure a specific sensitivity to B.C.G. and a positive reaction does not necessarily mean the presence of immunity against tuberculous infection. As, however, we have no laboratory tests which would measure immunity, this test is the nearest and best we have so far.

\section{Summary}

This report deals with an investigation to evaluate a tuberculin, prepared from the B.C.G. organism (B.C.G. tuberculin) on 987 subjects. In all these concurrent tests were performed with old tuberculin or P.P.D. by intradermal (Mantoux), percutaneous (jelly) or multiple puncture tests.

The tuberculin gave no false positive reactions in 191 subjects; it reliably detected tuberculin sensitivity in subjects with active or inactive tuberculosis and dose for dose was a more sensitive indicator of allergy than old tuberculin. Finally, it was a far more sensitive index of tuberculin conversion in
B.C.G. vaccinated subjects than the same dose of old tuberculin.

I wish to thank Dr. J. Ungar and Dr. P. W. Muggleton of Glaxo Laboratories who provided the B.C.G. tuberculin and who helped me with their advice; Dr. P. W. Gifford, Director of the Students' Health Service of the University of Sheffield, who kindly performed all tests on adults, Professor R. S. Illingworth and Dr. T. Colver and Dr. D. A. Anderson for access to their patients; Dr. P. C. Menneer, Tuberculosis Research Assistant, who assisted during this investigation, and the Research Fund of the University of Sheffield for their financial support, and Dr. Llywelyn Roberts, Medical Officer of Health of Sheffield, and Miss I. Littlewood, Superintendent Health Visitor, and their staff for their cooperation.

\section{REFERENCES}

Bluhm, I. (1949). Acta tuberc. scand., Suppl. 21, p. 24.

Hagberg, E. (1950). Acta paediat. (Uppsala), 39, 461

Heaf, F. (1951). Lancet, 2, 151.

Lind, P. and Holm, J. (1943). Acta tuberc. scand. 17, 237.

Long, D. A. Miles, A. A. and Perry, W. L. M. (1954). Bull. Wld Hith Örg., 10, 989.

Lorber, J., Farmer, P. and Muggleton, P. W. (1957). Tubercle (Lond.), 38, 227.

-, Hart, C. B. S.; Farmer, P. and Muggleton, P. W. (1956) Tubercle, (Lond.), 37, 187

Magnusson, J.' H., Lithander, A. and Hagberg, E. (1949). Ann. paediat. (Basel), 173, 253 .

Quaiser, K. (1954). Beitr. Klin. Tuberk., 110, 507.

Ruziczka, O. (1952a). Öst. Z. Kinderheilk., 8, 67. Ruziczka, (1952b). Wien. klin. Wschr., 64, 158. 